\title{
O Estresse das Avaliações de Ensino-Aprendizagem sobre o Psiquismo do Aluno
}

Francinete Alves de Oliveira Giffoni ${ }^{1}$; Lucas Macedo Bazerra ${ }^{2}$; Lindemberg Rocha Freitas ${ }^{3}$; Marlene Menezes de Souza Teixeira ${ }^{4}$

\begin{abstract}
Resumo: O presente artigo apresenta um breve comentário sobre a questão das avaliações escolares e seu impacto no psiquismo dos alunos, através de uma análise da literatura. Embora a avaliação possa parecer estimulante para alguns sujeitos, em alguns momentos, quando elaborada e aplicada de maneira mais coerente, sistemática e regular, tende a ser mais útil. Deveriam também serem aspectos intra-psíquicos e intra-pessoais dos sujeitos- alunos, bem como sua relação consigo mesmos, com os outros e com a escola.
\end{abstract}

Palavras-Chave: Avaliação, Estresse, Aluno.

\section{The Stress of the Teaching-Learning Evaluation about the Student of Psychism}

\begin{abstract}
This paper presents a brief comment on the issue of school reviews and their impact on the psychism of the students, through a literature review. Although the evaluation may seem exciting to some individuals, at times, when designed and implemented in a more coherent, systematic and regular way, tends to be more helpful. They should also be intra-psychic aspects and intra-personal-subjects of the students as well as their relationship with themselves, with others and with the school.
\end{abstract}

Keywords: Evaluation, Stress, Student.

\section{Introdução}

Num sistema educacional, assume grande importância a interação entre os elementos constituintes, aluno, família e escola, e a forma como estes elementos convertem seus atributos individuais em comportamentos comunicativos. Conforme a concepção de HALL e FAGEN (1969, p.109): (...) “Os objetos dos sistemas interacionais são melhor descritos como pessoas-comunicandocom-outras-pessoas “. É como se os sujeitos da relação não existissem por si mesmos, de forma isolada, e sim, somente adquirissem significado existencial na relação que estabelecem com os outros.

Importante contribuição destes autores é a compreensão de que as relações a serem consideradas quando se estuda determinado sistema, são aquelas que envolvem o conjunto dos objetos em torno de um problema que selecionamos como objeto sob o foco de nossa observação:

\footnotetext{
${ }^{1}$ Doutora em Educação pela Universidade Federal do Ceará - UFC. Professora da Faculdade de Medicina da Universidade Federal do Ceará; E-mail: francinetealves@gmail.com;

${ }^{2}$ Acadêmico de Medicina da Faculdade Christus - Fortaleza - CE. E-mail: lucasmacedobezerra@ hotmail.com;

${ }^{3}$ Professor. Doutor em Ciências e Tecnologia de alimentos;

${ }^{4}$ Graduada em Enfermagem pela Universidade Estadual do Ceará. Doutoranda em Educação e Ciências: Química da Vida e da Saúde, pela Universidade Federal do Rio Grande do Sul -UFRGS.
} 
(...) "sendo incluídas as relações importantes ou interessantes e excluídas as relações triviais ou supérfluas. A decisão sobre quais são as relações importantes e quais são as triviais compete à pessoa que trata do problema, isto é, a questão da trivialidade resulta ser relativa ao interesse da pessoa" (in WATZLAWICK, 1967, p.110).

Sabemos que as interações que o aluno estabelece nos diversos níveis de relações sistêmicas de que participa desde o início de sua existência, no imaginário dos pais, até o momento em que deixa a escola chegam a ser infinitas. Jamais tivemos, portanto, a pretensão, de que nosso trabalho pudesse abarcar toda a gama de variáveis relacionais envolvidas no complexo processo de desenvolvimento do sujeito-aluno e de suas vivências no contexto educacional. Procuramos nos deter na observação de aspectos comunicacionais emergentes da relação do aluno com a escola e a família, especialmente no que tange à formação de distúrbios psicossomáticos como sintomas de desadaptação.

As dificuldades enfrentadas pelo aluno, no contato com a escola, com a família e com a sociedade não serão analisadas pela fresta de um pensamento linear que compreende os fenômenos através do binômio causa-e-efeito. Optamos pela concepção de causalidade circular como eixo organizador de nossas idéias, devido à abertura perceptual e epistemológica que possibilita, como via de mão-dupla relacionando os fenômenos entre si , articulando-os com o todo.

Com o objetivo de clarificar o mais possível o desenvolvimento das ideias postas, utilizamos a abordagem sistêmica que inclui a teoria geral dos sistemas e a teoria da comunicação. Recorremos ainda, a título de referências complementares, duas outras abordagens, a psicodinâmica englobando a psicanálise, o psicodrama e a psicossomática e a teoria da inteligência emocional incorporada à teoria das inteligências múltiplas.

Através da conjugação dos pressupostos presentes nestas abordagens, pretendemos focalizar nossa atenção nas avaliações de desempenho escolar e seu potencial de patogenicidade sobre o funcionamento biopsicossocial do aluno.

\section{Contextualização}

Compreendemos que o modo como o sujeito acessa o conhecimento, como o manifesta e utiliza são plenamente influenciados pelo meio em que vive e pelas relações sócio-históricas que estabelece desde o começo de sua vida. Dessa forma, o contexto pode representar um fator de limitação ou de expansão para o processo de evolução intelectual. Por este motivo julgamos necessário determo-nos um pouco a refletir sobre a perspectiva social do desenvolvimento humano de forma mais genérica. 
A fim de esclarecer e aprofundar a questão da influência do momento histórico-político de cada contexto social sobre os processos educativos, trataremos agora de um estudo feito por MINDY LORNHABER e MARA KRECHEVSKY( in GARDNER, 1995). As autoras classificam a sociedade em dois tipos: a tradicional / agrária e a sociedade contemporânea / industrial. Em cada uma dessas formas de organização social, a educação sofre influências específicas e se delineia de maneira particular.

Na primeira, a busca maior é para garantir o suprimento alimentício, e as atividades centrais, giram em torno de religião, mito, música, dança e artes visuais, sendo os campos de conhecimento, plasmados por um sistema de valores assentados na religião e na ética , garantindo assim, a ordem social.

O ambiente onde as crianças crescem é estimulante para aquisição destas habilidades, e elas aprendem por imitação dos adultos em oportunidades práticas e repetidas, inclusive sob a forma de trabalho, o que reverte de imediato em benefício à comunidade. A instrução que as crianças recebem bem como a avaliação, acontece no contexto onde se executam trabalhos, nos diversos setores da sociedade. O encorajamento, o aconselhamento e a crítica contrutiva são utilizados como técnicas de ajuda.

Em sociedades deste tipo, a erudição não é considerada em si uma grande demonstração de inteligência. São considerados inteligentes e sábias as pessoas que apresentam virtudes morais e habilidades que lhes possibilitem uma boa convivência com outros pessoas, e a manutenção dos laços sociais, e da vida em comunidade, fator primordial para garantir a coexistência e assim a sobrevivência em grupo.

Outro tipo de organização social é a Sociedade Industrial, como o próprio nome sugere, aquela onde a ciência e a tecnologia preponderam. A complexidade econômica, trazendo a necessidade de inovações constantes exige a transmissão ultra-rápida de informações e a busca por novas formas de conhecimento. Estes são os elementos-chave da cultura, transmitidas às crianças. A erudição, plasmada na utilização da ciência linguística e da matemática, devido à demanda por novas invenções e a circulação de bens e serviços terceirizados, impulsiona pais e filhos numa árdua escalada de aperfeiçoamento intelectual.

A escola assume o papel de uma instituição formalmente comprometida com a manutenção do movimento em torno destes valores, que vão constituir as pilastras da construção dos currículos e o arcabouço ideológico dos instrumentos avaliatórios.

Diferentemente do que ocorre nas sociedades tradicionais, na escola da sociedade industrial as atividades didáticas em geral são descontextualizadas, ocorrendo dentro de seus muros ( ou muralhas), onde cada aluno defende seu espaço real e simbólico. São também delimitadas as formas de conhecer o mundo, através das noções de tempo, espaço, causalidade, fixadas em determinadas categorias de 
conhecimento, que obedecem a padrões e estereotipias conceituais. GARDNER (1994*) considera que o sujeito-aluno, nesse contexto, sofre “cerceamentos ontológicos” em que os objetos são definidos dentro de categorias amplas, a partir das quais vai construindo seu modelo de mundo. Dentro dessas categorias os objetos são classificados em " o tangivel " e o "intangivel ", "O vivo e o não-vivo, o sentimento e o não-sentimento". A partir do momento em que a realidade é compartimentalizada por estas ontologias conceituais, tornam-se possíveis certos tipos de comparações, enquanto outras, são excluídas. O educando terá opções de desenvolvimento intelectual dentro dessas coordenadas, a partir das quais formulará suas teorias sobre o mundo, a matéria, a vida, sobre o "si mesmo" e o "outro".

Os conteúdos curriculares são apresentados ao educando dentro de estilos cognitivos específicos, especialmente talhados com vistas às inteligências lingüística e lógico-matemática, o que poderá ter bons resultados se houver compatibilidade entre estes estilos e as potencialidades do sujeito, que terá então facilidade de assimilar a matéria dada e prestar exames sobre ela. Uma outra classe de cerceamentos existente nesse tipo de escola, é assinalada por GARDNER (1994*, p. 92):

"Considerações de etnia, classe social, estilos parentais e valores afetarão os tipos de
materiais com os quais as crianças se envolvem. (...) Do mesmo modo, suposições
feitas sobre quais as práticas são morais, como as crianças deveriam relacionar-se
com as outras ou com seus pais e o que são vestimentas adequadas ou boa
alimentação...(...) Na ausência de um firme reconhecimento e confrontação com tais
fatores predisponentes, entretanto, os jovens podem considerar-se
desconfortavelmente distantes da agenda escolar".

Podemos agora dimensionar melhor até que ponto o contexto sócio-histórico onde a escola se situa influencia o desenvolvimento da identidade do sujeito enquanto aluno e assim, através da história mapear o desenrolar dos diversos processos de ensino-aprendizagem pelo mundo e compreender como estes chegaram até nós. Considerando o Oriente e o ocidente como vertentes distintas de influências, podemos relacionar alguns fenômenos histórico-culturais que esboçaram o atual desenho do panorama educacional que hoje vivemos. À época da colonização do Brasil a igreja introduzia as idéias de Tomás de Aquino, cuja metodologia escolástica primava pela reprodução dos conteúdos escolares, enquanto procurava manter distante da consciência dos alunos a capacidade crítica. (...) “A educação dos jesuítas destinava-se à formação das elites burguesas, para prepará-las a exercer a hegemonia cultural e política. Eficientes na formação das classes dirigentes, os jesuítas descuidaram completamente da educação popular "(GADOTTI, 1993, p.72).

E, assim, por um longo período de tempo, conseguiram monopolizar o sistema educacional brasileiro, fato que deu origem a algumas das distorções ainda hoje presentes no contexto onde se dá a formação intelectual dos nossos alunos. 
Não é nosso objetivo, no entanto, entrar em maiores detalhes a respeito dos rumos pedagógicos que tomaram as instituições educacionais brasileiras, a partir de suas origens políticoideológicas.

sistema de ensino que temos e, que é resultante dos diversos processos sociais e históricos ocorridos nestes séculos.

\section{A Problemática vivenciada pelo sujeito-aluno}

Compreendemos que o educando, sujeito - bio-psico-social - ao ingressar no contexto da escola, deveria encontrar oportunidades abertas para construir-se através do ato de conhecer, desenvolvendo gradativamente seu potencial de sujeito histórico. A educação deveria ser colocada como instrumento de transformação social, possibilitando aos indivíduos o desenvolvimento de suas potencialidades e valores, o que os tornariam pessoas cada vez mais "...livres, conscientes, exigentes, participativas, questionadoras"..( BARRETO,1997,p.68). O conhecimento aí adquirido seria portanto uma mola propulsora de suas motivações naturais para um realização plena.

No entanto, o que acontece ao sujeito-aluno na escola-contexto que ora se nos apresenta? Suas chances de alcançar um desenvolvimento integral de forma mais espontânea ficam resumidas, aos moldes dos processos educativos, à forma como os conteúdos tem sido veiculados e às avaliações às quais se submete involuntariamente.

No atual modelo pedagógico adotado pela escola brasileira, todo o aparato psíquico do sujeito deve estar disponível para absorver as programações instituídas, apropriadas às necessidades criadas pelo sociedade. A busca individual pelo conhecimento e as motivações internas devem ser atreladas aos conteúdos curriculares. A avaliação do desempenho escolar é uma rotina já incorporada ao processo ensino-aprendizagem desde o planejamento, passando pela elaboração dos currículos e culminando com a triunfal testagem dos rendimentos obtidos pelo aluno, no período das avaliações propriamente ditas, ao final de cada bimestre, ano letivo e especialmente no vestibular.

Se prestarmos atenção, veremos que se tornam hoje oportunas as seguintes palavras:

(...)"A tendência, hoje, é a de abolir qualquer tipo de escola "desinteressada"( não imediatamente interessada) e "formativa", ou conservar delas tão-somente um reduzido exemplar destinado a uma pequena elite de senhores e de mulheres que não devem pensar em se preparar para um futuro profissional, bem como de difundir cada vez mais as escolas profissionais especializadas, nas quais o destino do aluno e sua futura atividade são predeterminados ". (GRAMSCI, In: GADOTTI - 1995, p.140). 
E o educando não pode se furtar a essa escalada. O seu crescimento ocorrerá dentro desta escola e será portanto, plasmado pelo sistema de valores a que estamos nos referindo.

Utilizemos o pensamento de HALL e FAGEN in: WATZLAWICK, (1967), quando definem um sistema como um conjunto de objetos entre os quais se estabelecem relações. Segundo estes autores, as relações podem ser estabelecidas entre os próprios objetos ou entre seus atributos, que são propriedades, que os caracterizam, especificam. Estendendo essa linha de raciocínio para o caso do sistema educacional teríamos como objetos a escola, o aluno, a família e a própria sociedade, cada qual com seus atributos específicos, realizando um determinado papel funcional. Ao examinarmos a problemática relacional existente no contexto educacional, ao invés de estudarmos cada elemento em separado, consideraremos as relações que se dão entre os elementos constituintes do sistema como nosso campo de estudo, uma vez que essas relações dão a coesão ao sistema como um todo e sua compreensão é condição essencial à percepção mais próxima à totalidade do fenômeno.

O aluno, por este prisma é fragmento de uma realidade inteira, da qual nem sempre nos apercebemos. Ele busca na família, na escola e na vida algo que lhe falta, como se procurasse reunir partes, para constituir o seu ser. Se ele fala ou não fala, se tem sintomas ou grita, se guarda mistérios ou se os revela, não está sozinho, é um elemento de um sistema dinâmico. E , dessa forma, será nosso objeto de estudo, um objeto dotado de certo encantamento, e que vem ao nosso encontro, para que dele façamos uma apreciação. Ao realizarmos este trabalho, de certa forma, passamos a fazer parte de seu circuito relacional, tornando assim, também nossa a sua realidade.

E não poderíamos fugir a essa complexidade que a nosso ver desnuda nuanças do fenômeno em foco, e, sem o que, não poderíamos formular uma compreensão aproximada da realidade vivida pelo aluno, enquanto ser bio-psico-social.

A família aparece como contexto determinante de potencialidades, participando de forma decisiva no desenvolvimento da inteligência emocional, na estruturação do ego e dos papéis sociais. Para entender sua influência, ora potencializadora, ora cerceadora do processo de diferenciação pela qual passa o sujeito rumo à sua individuação.Tudo isso nos remete a um nível meta de relações dialéticas em que vemos o aluno, em suas diversas dimensões: corporal, psíquica, social e sistêmica. No processo de desenvolvimento do corpo e da mente, essas dimensões se acham inseparavelmente conectadas através de uma série de combinações que vão se estabelecendo ao longo do tempo.

GESELL (1985), explica que cada ato ou movimento que vai sendo definido é um esquema de comportamento que se organiza, uma resposta corporal específica a um determinado estímulo. Desde os mais simples movimentos como acompanhar com os olhos um objeto, que o bebê realiza precocemente, até os mais delicados atos da vida adulta, cheios de simbolismo, já impregnados por experiências pessoais, sociais, culturais, obedecem à mesma lei. Assim, GESELL (1985) considera que 
existe uma programação biológica para o desenvolvimento humano mas relaciona-a sempre às influências ambientais.

Para ele, o ambiente é um fator de vital influência, atuando sobre o potencial genético herdado. Explica que há dois tipos de herança a serem considerados: uma herança ancestral que é transmitida e se revela nos processos de maturação e uma herança social, cujo modo de transmissão ocorre por aculturação. Esses dois processos, maturação e aculturação, se entrelaçam na formação de um mesmo ser.

Afirma ainda que o crescimento dá-se do simples para o complexo, em fases e ciclos pelos quais passa a criança desde a vida intra-uterina até os 10 anos de idade, aproximadamente. Vale ressaltar que, embora seja estruturalista, não se deixa enganar com a idéia de um desenvolvimento linear, estratificado, conforme esclarece que (...)"as normas etárias e os perfis de caráter normativo não devem ser tomados demasiado ao pé da letra (1985, p.26).

Em sua abordagem, diz que os pais não devem preocupar-se quando o filho não se encontre, em todos os aspectos, à altura do um comportamento normativo descrito por ele, dentro de um certo nível ou padrão esperado em cada fase. Neste ponto toca a questão da expectativa dos pais quanto ao desenvolvimento de uma criança, quando muitas vezes comparam-na com alguma outra criança da mesma idade ou a submetem a uma escala estatística de valores a serem atingidos como peso, estatura, desempenho neuro-muscular, partindo daí para o desempenho intelectual. Para este autor, os pais e professores devem ser facilitadores do processo de crescimento, que é individual e específico para cada sujeito.

A nosso ver, as pessoas que se propõem a avaliar o processo de desenvolvimento de uma criança, devem estar atentas às nuanças teóricas, cotejando-as com a visão pragmática do fenômeno existencial, observando a criança, com atenção às suas demandas e às necessidades que vão se apresentando ao longo do tempo, em cada fase.

A tarefa de acompanhar e facilitar o desenvolvimento de determinada criança, envolve percepção acurada e amadurecimento emocional por parte dos adultos, no sentido de controlar seus próprios desejos e ansiedades para não prejudicar a evolução natural da individualidade. Para que o processo se dê naturalmente, o ambiente para ela deve ser agradável, afetuoso, com a estimulação necessária.

Podemos estender essas considerações ao desenvolvimento da criança, na escola lembrando GESELL (1985):

(...) "Não deve ser feito com uma ênfase deliberada no chamado desenvolvimento cognitivo da criança, nem com a falsa esperança de poder acelerar consideravelmente o seu desenvolvimento ou de a tornar mais inteligente do que a natureza quis, originariamente, que ela fosse ". (Grifo do autor) $(1985, \mathrm{p} .12)$. 
E, em outro trecho, quando reitera:

(...)"Tanto quanto sabemos hoje, enriquecer o ambiente da criança e oferecer-lhe as maiores oportunidades possíveis permitem-lhe dar o melhor de si própria, mas não a tornam 'melhor', nem mais inteligente ou mais ágil de espírito do que, ao nascimento, estava destinada a ser”. (1985, p.15).

O autor está alertando para o fato de que cada criança tem um potencial e deve desenvolver-se conforme sua natureza permite.

Considerando o ambiente escolar, imaginemos como deve sentir-se o sujeito para quem se dirigem pais e professores ansiosos por sucesso, numa espera silenciosa mas cheia de cobranças! Ele terá duas alternativas: a primeira é a de buscar atender essas expectativas, se esforçando ao máximo, deixando de lado seus próprios anseios e necessidades do momento para trilhar todo o processo que o levará àquele premeditado sucesso. E poderá ter êxito. Será reforçado para isso, recebendo elogios, afagos e gratificações por vezes fantásticas. Seguindo assim, com o tempo terá modificado boa parte de seu próprio eu, num processo que poderá custar um alto preço para a economia psíquica, levando a desvios de personalidade e, principalmente, sentimentos de não realização e insatisfação, derivando para o campo das neuroses.

Uma segunda opção seria a de recusar-se a assumir o papel traçado para ele neste script. Não se importaria com as mensagens implícitas ou explicitas que lhe mandassem pais ou professores no sentido de forjar seu modelo de desempenho. Ouvindo a voz de seu íntimo, seguiria o caminho ditado pela própria consciência, atendendo às próprias necessidades de crescimento e desenvolvimento, de acordo com suas potencialidades inatas. Estaria em contato consigo mesmo, sem conflitos internos, embora pudesse causar estremecimento na relação com aquelas pessoas que o queriam diferente.

Somente famílias bem estruturadas, no que diz respeito à maturidade afetiva dos pais, estabelecem normas coerentes e flexíveis, oferecendo ao indivíduo condições de se opor aos valores vigentes, aceitando as características individuais de seus membros e estimulando desde de cedo o desenvolvimento da inteligência emocional

Neste momento inserimos a reflexão sobre o significado da aprendizagem para a vida psico-afetiva do indivíduo. Que motivações conduzem uma pessoa à busca de conhecimento? Que função este conhecimento adquirido vai assumindo no processo de diferenciação da personalidade?

M. KUPFER (1992), estudando como a criança desenvolve a motivação natural pelos estudos, sugere que os questionamentos da criança são inicialmente sexuais e que se evidenciam a partir da angustia de castração que FREUD(1976) associa a Angustia de Perdas, e que aconteceria geralmente após os 2 anos de idade. A partir daí, um outro momento importante é o da elaboração do Complexo de Édipo: 
(...) “ o processo através do qual uma menina se define como mulher e o menino como homem (ou vice-versa), depois de terem extraído das relações com o pai e a mãe as referências necessárias a essa definição". (M. KUPFER, 1992, p. 80).

A criança, ao perceber as diferenças sexuais, entra num Estado de angústia que a mobiliza no sentido de "querer saber" e prepara sua mente para caminhar rumo ao conhecimento.

Uma criança de 5 anos, por exemplo quando questiona diversas coisas, está fazendo investigações sexuais. Estaria tentando definir seu lugar no mundo, um lugar, a princípio, sexual, e relacionado ao triângulo pai - mãe - filho. Este questionamento teria como base o desejo dos pais, sob a tonalidade afetiva das relações familiares.

Segundo a interpretação desta autora, o Édipo está presente de uma outra forma nestas perguntas: "De onde viemos? "Para ele, o de onde viemos eqüivale a qual é a minha origem em relação ao desejo de vocês?; Porque me puseram no mundo, para atender quais expectativas e esperando que eu me torne o quê?" Essa parte final eqüivalendo à questão: para onde vamos?

Por volta dos 7 anos, idade em que geralmente se inicia o período escolar propriamente dito, espera-se que o conflito Edipiano seja elaborado por um mecanismo de defesa do ego, a repressão, ou por outra, que parte dele seja transformado pela sublimação em Pulsão de Saber, de dominar. Não que a educação formal seja o fator determinante desse processo. Nesta fase a própria constituição egóica da criança tende naturalmente a substituir as questões da sexualidade através de um deslocamento, passando si interessar por objetos não-sexuais, daí um certo ar de curiosidade nas crianças escolares. FREUD relacionou com esse fenômeno 2 tipos de pulsões: A pulsão de domínio e a pulsão de morte, paradoxalmente identificados com o saber e com a vida, atando as pontas dos fios do desenvolvimento sexual e cognitivo.

A teoria psicanalítica postula que:

(...) "o movimento em direção ao conhecimento é antes de tudo sexual. O desenvolvimento intelectivo sério inicialmente sexual, supondo transformações na forma como se apresenta nos diversos fases da infância e da adolescência, através dos mecanismos de defesa do Ego, que os transforma em pulsões que levam a criança a desejar aprender ”.(MANONI.O., In: M. KUPFER, p.84).

O trajeto existencial do indivíduo dependerá das conquistas afetivo-cognitivas no início de sua vida. Daí a importância de analisar minuciosamente o processo de diferenciação do ser humano e as condições básicas exigidas pela natureza para que este seja satisfatório.

Buscando penetrar nesse misterioso campo das origens da vida psíquica e o tecido primordial das relações descreveremos sucintamente os fenômenos iniciais da formação do mundo subjetivo, de como a biologia chega à psicologia, transformando um construto anatomofisiológico num ser biopsicossocial. Utilizaremos a Teoria da Programação Cenestésica, de VICTOR DIAS 
(1994), pelas contribuições trazidas para o aprofundamento no estudo daquilo que acontece dentro do psiquismo nas fases precoces da vida.

A filogenia garante aos animais, desde o nascimento uma preponderância de marcadores biológicos que lhe possibilitam um certo grau de autonomia que asseguram a sobrevivência e que se instalam de forma quase que imediata. $\mathrm{O}$ homem, ao contrário, nasce imaturo, dependente, imerso no mundo e confundido com ele. As características humanas desenvolvem-se por ativação de potenciais herdados, num minucioso processo de elaboração, que se dá única e exclusivamente numa relação : a simbiose mãe-filho. A mãe biológica ou pessoa cuidadora é a primeira e mais importante influência na formação da personalidade, a "Matriz da Identidade”(MORENO [1983]), influência que se estende depois ao pai, aos irmãos e à família como um todo. Neste processo de humanização, cruzam-se a filogênese a ontogênese.

No início, o mundo chega ao bebê através da mãe, sendo a relação possível graças aos órgãos dos sentidos, já que as funções superiores ainda estão sem funcionamento, exceto os vagos registros da vida intra-uterina, sob forma de memórias sensoriais, desintegradas da realidade global. O sensorial assume a presidência da relação mãe-filho, permitindo a penetração dos estímulos que virão ativar os potenciais genéticos. Para que os estímulos atinjam o universo perceptual do recém-nascido, precisam vencer o que se chama de filtro ou barreira do estímulo, uma espécie de lei neurológica que controla o que deve e o que não deve chegar ao bebê. E esta lei funciona de acordo com a natureza, com a maturação gradual porque passa o seu sistema nervoso.

No estudo da fisiologia, chamam-se estímulos proprioceptivos aqueles que indicam a posição das partes do corpo, e outras informações vindas de dentro do organismo como aquelas relacionadas à bioquímica, à pressão e a temperatura. Estes receptores, fazem parte do sistema interoceptivo, que desde os primeiros momentos de vida, estão ativados e mandam mensagens ao cérebro. Por isso é que o bebê recebe quase exclusivamente mensagens que vem do seu interior como a fome, a posição, a dor, estando preparado apenas para uma relação bem próxima. Perceberá a mãe pelo toque, uma vez que a pele também possui esses tipos de receptores.

Um outro sistema responsável para levar mensagens ao cérebro é o esteroceptivo, que é responsável pela transmissão de estímulos como som e luminosidade. Este grupo de receptores está bloqueado ao nascer, como forma de proteção, para garantir que a atenção do bebê esteja especialmente voltada para seu interior e para sentir a presença da mãe. Ele terá mais facilidade de perceber suas sensações viscerais, principalmente no trato digestivo superior, boca e estômago, órgãos de prioridade para o desenvolvimento corporal e afetivo no início da vida.

A vida humana requer a interação do emocional com o racional. No processo de evolução das civilizações, as regras sociais ditadas pelo intelecto tendem a conter os excessos emocionais e os 
impulsos instintivos. Porém não devemos esquecer que as emoções, pela própria origem latina da palavra cuja raiz é movere e indica uma tendência para a ação, nos proporcionam tomadas de atitudes para resolver situações inusitadas durante a vida. A dissociação entre uma emoção e sua reação correspondente é um dos resultados do próprio processo de civilização, como também as anomalias comportamentais individuais e sociais. GOLEMAN (1995) afirma que as tendências biológicas para agir são moldadas pela experiência e sofrem influência direta da cultura. Os valores sociais e históricos presentes em cada contexto determinam a forma como os indivíduos modelam sua expressão emocional e, de acordo com as situações e com o potencial afetivo e cognitivo de cada um, suas reações emocionais e suas decisões "racionais" serão mais ou menos adequadas.

GOLEMAN (1995) refere-se a pesquisas realizadas em Harvard, avaliando pessoas de meiaidade com altos índices de QI nas faculdades de elite. Estas pessoas que na vida acadêmica, tiravam as melhores notas, e que apresentavam sucesso em termos de salário, produtividade e status em seu campo profissional, e no entanto não encontravam satisfação na vida cotidiana, nas amizades, na família e nas relações amorosas. Relata ainda os resultados de um estudo realizado através da University of Massachussets, com 450 garotos imigrantes acompanhados até a idade adulta. O estudo revelou que o QI não tem uma relação direta com o sucesso no trabalho. Aptidões emocionais como capacidade de lidar com frustrações, controlar impulsos, compreender-se e relacionar-se com outras pessoas, parecem algumas vezes até mais importantes para o bom desempenho do papel profissional.

A conclusão a que estas investigações levaram é a de que a inteligência acadêmica não significa preparo suficiente para as vicissitudes da vida. Novos estudos vem abrindo espaço na ciência para incluir afetividade e emoção ao lado da inteligência, quando pensamos e repensamos o ser humano.

\section{A Inteligência Emocional: Implicações pedagógicas}

A inteligência emocional é, em última análise, o conhecimento de nosso funcionamento psico-afetivo, associado à utilização construtiva do mesmo. A não estimulação desse autoconhecimento na família e na escola, conforme vem se constatando nas pesquisas supracitadas tem levado a sérios prejuízos sociais.

Sabemos que experiências negativas, frustrantes ou traumáticas podem ser reprocessadas e ressignificadas através do reaprendizado efetivo. Ao mesmo tempo que potencialidades como empatia, solidariedade, iniciativa, podem ser despertadas. Fatores que venham a impedir de alguma forma o desenvolvimento dessas capacidades podem causar anomalias para o indivíduo e entraves para a sociedade. 
A teoria das inteligências múltiplas postula que o ambiente deve proporcionar ao indivíduo oportunidades diversificadas de estimulação, respeitando as potencialidades genéticas e as fases do desenvolvimento de cada tipo de inteligência. O desenvolvimento harmonioso de um indivíduo, comportaria a estimulação de suas diferentes potencialidades, especialmente a inteligência emocional. A escola como extensão da matriz de identidade que é a família, deveria portanto levar os indivíduos ao aperfeiçoamento, enquanto seres transcendentes dotados de sentimentos, além da razão e do intelecto. E como se posiciona a escola que temos hoje diante dessas proposições e dos questionamentos daí derivados?

A vivência hoje nas escolas, com raras exceções, está muito distante desse ideal. Uma vez matriculadas, as crianças passam a fazer parte de um sistema educacional rígido, sendo comprimidas dentro dos esquemas curriculares, submetidas a avaliações de conteúdos específicos que devem ser assimilados a qualquer preço.

Um contexto escolar que segue esses princípios parece ignorar os avanços na conceituação da inteligência, como a noção das inteligências múltiplas e da inteligência emocional e a importância destes avanços para o processo ensino-aprendizagem.

Procuramos investigar na pesquisa em escolas de Fortaleza até que ponto os alunos têm desenvolvido a inteligência emocional. Neste sentido tentamos encontrar evidências de que o aluno tem-se observado quanto ao seu próprio desenvolvimento cognitivo, perguntando sobre a média de suas notas nas provas, com que frequência ficavam de recuperação e se repetiram alguma série, e ainda se t6em observado quais as matérias em que sentem mais dificuldade.

Os resultados apontam no sentido de que os alunos entrevistados demonstram considerável auto-percepção, no que tange ao seu papel de aluno, quando indagados sobre sua vida estudantil. 4,9 $\%$ referem tirar notas, geralmente entre 0 e 4 ; as notas entre 5 e 7 , foram encontradas em $59,8 \%$ e acima de 8 , em 35,3\% dos sujeitos. Cerca de 50,0 \% já ficaram de recuperação, e 32,9\% já repetiram alguma série. As matérias apontadas como maior nível de dificuldade foram matemática e português, justamente aquelas consideradas no contexto escolar como básicas e mais importantes!

Observando esses dados iniciais podemos tecer algumas considerações. Uma frequência de repetência de 32,9 \% e o maior percentual de notas entre 5 e 7 (59,8\%) nos faz crer que as restrições criadas pela sistematização curricular e pelo atual processo ensino-aprendizagem, incluindo a forma como tem se dado as avaliações escolares são potencialmente provocadoras de alterações no equilíbrio psíquico e até orgânico dos alunos, especialmente para aqueles que não dispõem de uma razoável estrutura psico-afetiva, desenvolvida dentro de condições satisfatórias como as que descrevemos no capítulo 1.

Esperamos, no entanto que gradativamente o conceito mais abrangente de inteligência seja incorporado à educação como já vem acontecendo em diversos campos de abordagem humana , uma 
vez que não mais se sustenta a idéia da razão em antagonismo às emoções e sim que os dois cérebros, racional (córtex pré-frontal ou Néo-córtex) e emocional (amígdala e sistema límbico) apresentam suas individualidades, e devem ser vistos integrados, e estimulados a trabalhar em harmonia. E, embora no meio científico possa ainda estar sendo ressaltado ora aspecto emocional ora o intelectual, com a primazia deste último, a aceitação cada vez maior da interação entre essas duas regiões revelada na complementariedade das funções a elas relacionadas vem ampliando a compreensão do potencial humano e de sua totalidade existencial.

Uma das principais contribuições dessa forma de abordagem à área pedagógica reside na instituição da crença e na constatação de que, além do que aprendemos normalmente na escola, podemos realizar um "aprendizado emocional" (GOLEMAN,1995), em qualquer fase da vida, resgatando possíveis falhas, que tenham havido na relação com a matriz de identidade e no desenvolvimento da personalidade.

O aprendizado de como funciona nosso cérebro, no aspecto emocional, além do aspecto cognitivo, deve ser buscado por uma escola que se pretenda coerente com as mudanças paradigmáticas de nosso tempo. Este é um conhecimento que pode nos informar sobre o passado que vivemos o presente que estamos fazendo e o futuro que deveremos ter.

\section{A Escola e o Estresse diante das avaliações}

$\mathrm{O}$ encadeamento de nossas idéias faz-se no sentido de dar um contorno à questão dos conflitos que povoam os ambientes escolares, segunda matriz de identidade, onde se continua o processo de construção do sujeito - aluno.

A questão da motivação pelo estudo merece destaque quando investigamos os problemas emergentes na vinculação do aluno à escola, no processo de adaptação ao sistema de ensinoaprendizagem e às avaliações escolares.

O desejo pode ser o ponto de partida de um estado de estresse. Principalmente quando se impõe diante dele um impedimento. Quantos alunos haverá que "desejam" ardentemente fazer uma prova? Acreditamos que, poucos tenham essa vontade. O desejo que sentem em geral é outro, que poderia ser traduzido assim, na linguagem deles: "vontade de sumir", "vontade de brincar, de faltar, de ir à praia, de esquecer, de rasgar a prova". São vontades divergentes daquilo que a realidade exige: ficar ali e resolver os quesitos para tirar a nota, prestar contas...

É verdade que este não seria um estresse capaz de gerar uma cascata de reações psicoorgânicas, se ocorresse apenas uma vez, mas , multipliquemos por 10, por 100 e até por 1000 vezes esses pequenos contragostos na vida de um estudante. E depois somemos a todos os fatores já citados, 
como os questionamentos internos de quem se pergunta "por que estou aqui? Para que vou ao colégio? O que eu quero mesmo? Por outro lado a pressão social: "Hoje em dia quem não se forma vai ser gari", e as expectativas familiares: "Não vai decepcionar o vovô, vai?" E para quem tem bolsa de estudos: "cuidado para não perder, hein..." ou se é o melhor da classe: "Até você, está com medo? ". Que organismo suporta esse dia a dia, anos a fio, sem sofrer nada?

Diante do conflito entre o desejo interno de lutar contra a repressão de um sistema rígido, o ego busca subterfúgios e, não encontrando escapatória, muitas vezes usa como defesa o sintoma.

Se o aluno tivesse liberdade para decidir consigo mesmo, de acordo com suas pulsões instintuais, com seu desejo, as áreas de estudo que mais lhe interessariam, ainda assim poderia ter conflitos internos entre o ego e o id. Isso já seria suficiente para gerar um grau de tensão interna que poderia resultar na formação de algum sintoma. Somam-se ainda as solicitações do ambiente, as imposições culturais e no caso do aluno na escola, ainda as exigências do currículo, como fontes de pressão externa.

O ego muitas vezes se adapta, assimilando essas solicitações externas, que são introjetadas e passam a ser sentidas como se partissem dele mesmo. Os impulsos do id sofrem a ação de mecanismos de defesa do ego como repressão, negação ou sublimação.

Existem momentos, no entanto, em que o aluno se encontra com dificuldades relacionais com os pais, com algum professor e até com os colegas da mesma idade e ocorrem falhas nos mecanismos de defesa do ego, principalmente quando estes não foram bem formados na matriz familiar. Nestes casos, os impulsos do id não ficam totalmente esquecidos, reprimidos ou sublimados. Eles tendem a incomodar o ego, para serem realizados, gerando conflitos. O sujeito sente angústia mas não identifica do que se trata. $\mathrm{O}$ ego tenta conciliar o desejo interno com a exigências da família e da escola. Quando o conflito se torna insustentável, começam a surgir os sintomas, que podem evoluir para doenças psicossomáticas ou derivar para neuroses.

O estudo desses quadros psicopatológicos assume importância, no sentido pensarmos de forma preventiva ficando em alerta para o aspecto evolutivo das neuroses e para a forma adequada de lidar com a criança que apresenta problemas diante do estresse das avaliações escolares.

WATZLAWICK (1967) refere-se aos estudos de FROMM-REICHMANN (1942) que evidenciaram o uso de sintomas como comunicação e de JACKSON ( 1954), que indicam a utilização pelo paciente de sintomas na comunicação com sua família, concebendo um sintoma como uma mensagem não-verbal.

A nosso ver é preciso antes parar e pensar no que estivemos fazendo no passado, até agora. Refletir acerca dos erros e acertos, que vêm demarcando a educação brasileira através do tempo.

Hoje percebemos que a avaliação pode ser até estimulante para alguns sujeitos, em alguns momentos, e talvez o fosse para todos se aplicada de forma individualizada, respeitando as condições 
em que cada aluno se encontra ao ser avaliado, suas potencialidades, seus limites e a condição do meio ambiente onde ele está inserido e onde se realiza esta avaliação. Os códigos simbólicos que facilitariam a manifestação dos diversos aspectos de sua inteligência deveriam ser utilizados, sob um clima afetivo de aceitação e incentivo. Tudo isso colaboraria com o ego do aluno, que não se sentiria ameaçado, ao ser testado da forma como, algumas (inúmeras) vezes lhe acontece.

Uma avaliação coerente, sistemática, regular, útil à comunidade, ao invés de dar-se num espaço-tempo demarcado, deveria ser feita, dentro do possível, em um ambiente sentido pelo aluno como natural, um contexto adequadamente pragmático. Deveriam ser avaliados, em especial, os aspectos intra-psíquicos e intra-pessoais dos sujeitos- alunos, sua relação consigo mesmos, com os outros e com a escola.

\section{Referências}

ANDRADE, T.M. Psicanálise e psicossomática. Coleção psicanálise da Criança, Salvador : Editora Álgama, 1993

ASSIS, M. Memórias póstumas de Brás Cubas - Obras completas de machado de Assis. São Paulo: Editora Formar, 1986.

ÁVILA, L. A. Doenças do corpo e doenças da alma. Investigação psicossomática e psicanalítica. São Paulo: Editora Escuta, 1998.

BANKS L. L. (ORG.) Percursos Piagetianos. São Paulo: Cortez Editora,1997.

BARRETO, A . P. Manual do terapeuta comunitário. Curitiba: Editora Pastoral da criança, 1999.

BENJAMIM, W. Reflexões: A Criança, o brinquedo e a educação. São Paulo: Editora Summus, 1984.

BENOIT, P. Psicanálise e medicina: Teoria e casos clínicos. Rio de Janeiro: Jorge Zahar Editor, 1989.

BERMUDEZ, R.J.G. Núcleo do Eu. São Paulo: Editora Natura, 1978.

BUCHVITZ, P. A. Sublimação da sexualidade infantil. Psicanálise de Criança. São Paulo: Editora Escuta, 1998.

CAIN, J. O campo psicossomático. Rio de Janeiro: Editora Beertrand do Brasil, 1996.

CAPRA, F. A Teia da Vida - Uma nova compreensão científica dos sistemas vivos, São Paulo: Editora Cultrix, 1996.

DANTAS, H. A infância da razão. Uma introdução à psicologia da inteligência de Henry Wallon. São Paulo: Editora Manole, 1990. 
DEJOURS, C. Repressão e subversão em psicossomática. Investigações psicanalíticas sobre o corpo. Rio de Janeiro: Jorge Zahar Editor, 1991.

DIAS, V. R. C. Análise Psicodramática. Teoria da Programação Cenestésica. São Paulo: Editora Ágora, 1994.

FREUD, S. Extraída da edição standard brasileira das obras psicológicas completas de Siegmund Freud. Livro 24 e 25. Um estudo autobiográfico e outros trabalhos. Coordenação Editorial de Pedro Paulo de Sena Madureira. Rio de Janeiro: Imago Editora, 1976.

FREUD, S. Conferência XXIII - Os caminhos da formação dos sintomas Edição standart brasileira das obras psicológicas completas de Siegmund Freud, Pags. 419-439, Vol. XVI- 2a edição. Rio de Janeiro: Imago Editora, 1994

GADOTTI, M. História das Idéias Pedagógicas. São Paulo: Editora Ática, 1993.

GAMA, M. C. S. A teoria das Inteligências múltiplas e suas implicações para a educação. Temas sobre Desenvolvimento. Vol. 3. N. 14 pág. 4-9. Porto Alegre: Editora Artes médicas, 1993.

GARCIA-R. Freud e o Inconsciente - 8a edição, Rio de Janeiro: 1993, Jorge Zahar Editor.

GARDNER, H. Estruturas da mente - A teoria das inteligências múltiplas. Porto Alegre: Editora Artes Médicas, 1994.

GARDNER, H. Inteligências múltiplas: A Teoria na Prática - Porto Alegre: Editora Artes médicas, 1995.

GARDNER, H. A criança pré-escolar: Como pensa e como a escola pode ensiná-la. Porto Alegre: Editora Artes médicas, 1994.

GARDNER, H. A nova ciência da mente. Uma história da Revolução Cognitiva - São Paulo: Editora da Universidade de São Paulo, 1995.

GESELL, A. - A Criança dos 0 aos 5 anos. São paulo: Editora Martins Fontes, 1985.

GOLEMAN, D. Inteligência Emocional - A teoria revolucionária que redefine o que é ser inteligente. Rio de Janeiro: Editora Objetiva, 1995.

GRODECK, G. Estudos psicanalíticos sobre psicossomática, São Paulo: Editora Perspectiva, 1992.

GRÜNSPUN, H. Distúrbios Neuróticos da Criança. $4^{\text {a }}$ Edição, São Paulo: Livraria Atheneu, 1985.

GUYTON, A.C. Tratado de Fisiologia Médica. Rio de Janeiro, Editora Interamericana 1976.

HESSE, H. - Sidarta. 36a Edição. Rio de Janeiro: Editora Record, 1995.

KOSSAK- ROMANACH, A. Homeopatia em 1000 conceitos. São Paulo: Elcid Editora, 1984

KRETSCHMER, E. - Psicologia Médica . 13ª Edição, São Paulo: 1974, Atheneu Editora 1974. 
KRYNSKI, S. (coordenador). Psiquiatria Infantil: Aspectos terapêuticos- Monografias Médicas, Série pediatria, Vol. 9., São Paulo: Editora Sarvier 1976.

KUPFER, M. C. Freud e a educação - O Mestre do Impossível. Série - Pensamento e Ação no Magistério, - 2 $2^{\text {a }}$ Edição. São Paulo: Editora Scipione 1992.

LALIVE, M.D.E. Grodeck, a doença como linguagem, São Paulo:Editora Papirus, 1988.

LECLAIRE, S. O corpo erógeno. Uma introdução à teoria do complexo de Édipo- São Paulo: Editora Escuta, 1992.

MARIANO J. R. Fisiologia das Emoções - Introdução à neurologia do comportamento, anatomia e funções do sistema límbico. - São Paulo: Editora Sarvier,1975.

MORENO, J. L. Fundamentos do Psicodrama. São Paulo: Summus Editora,1983.

PACHECO, A.C. Medicina Psicossomática. 2a Edição. São Paulo: Editora sarvier, 1976.

PENNA, C.R. Medicina Antropológica -S.Paulo: Editora Sarvier, 1976.

PIAGET, J. Seis estudos de psicologia. 22a edição. São Paulo: Editora Forense,1977.

PICHON-R. E. Teoria do Vínculo - Coleção Psicologia e Pedagogia - $2^{a}$ Edição - São Paulo : Martins Fontes, 1986.

REIMÃO, R. e DIAMENT, A. J. Sono na Infância - Aspectos normais e principais distúrbios. Monografias Médicas, série pediatria Vol. 25. São Paulo: Editora Sarvier, 1985.

SCHILLER, P. O médico, a doença e o inconsciente. A Psicossomática à luz da Psicanálise. Rio de Janeiro: Editora Revinter, 1991.

VIGOTSKY, L. Pensamento e Linguagem. Lisboa : Editora Antídoto,1979.

WALLON, H. - A Evolução Psicológica da Criança. São Paulo, Livraria Martins Fontes, 1968.

WALLON, H. As origens do caráter na Criança. S.Paulo: Editora Difusão Européia do livro, 1971

ZAZZO, R.. Manual para o exame psicológico da criança. São Paulo, Mestre Jou Editora, 1981.

\section{Como citar este artigo (Formato ABNT):}

GIFFONI, F.A.O.; BEZERRA, L.M.; FREITAS, L.R.; TEIXEIRA, M.M.S. O estresse das avaliações de ensinoaprendizagem sobre o psiquismo do aluno. Id on Line Revista de Psicologia, Fevereiro de 2015, vol.9, n.25, p. 226-242. ISSN 1981-1189. 